III Simpósio Paranaense de Modelagem.

Simulação e Controle de Processos

Artigo: 28

ISSN : 1984-7521

Póginas: 206-213

\title{
Optimization and Modelling of a CSTR Reactor Using Numerical Methods
}

\author{
Lana Matheus Luiz, Martim Emerson \\ Pontifical Catholic University - PUCPR - PR, matheusluiz.15@hotmail.com
}

\begin{abstract}
This report deals with differential equations and how they can be used to help the chemical engineer to size and optimize a CSTR reactor. The purpose of this article is to demonstrate the behavior of an elementary reaction where A forms B, in a first order reaction, to use the numerical methods of Euler and Runge Kutta to do so and to evaluate thermodynamic parameters of the reaction. These equations relate several characteristics of a fluid and for the type of specific reaction are tested to obtain the profile of $\mathrm{Xa}, \mathrm{Xb}$ and $\gamma$, these being, dimensionless, that for $\mathrm{Xa}$ and $\mathrm{Xb}$ show how $\mathrm{A}$ is spent and $\mathrm{B}$ is produced and $\gamma$ serves to relate the input temperature and at a certain point in the reactor. For the stationary solution, the bisection method was used to find the $\gamma$ and then $\mathrm{Xa}$ and $\mathrm{Xb}$. To solve the differential equations, the Euler and Runge-Kutta methods of the 4th order were used. From this the profiles were evaluated, and a great "sensitivity" was verified in the equations, since any change of parameters affected drastically in the iterations of the numerical methods. However, it was possible to find values for $\mathrm{Xa}, \mathrm{Xb}$ and gamma that made chemical and mathematical sense for both a theoretical and a practical example (cyclopropane $\rightarrow$ propene). It was possible to evaluate the decay and ascent profiles of reagents and products using Excel as a tool, and the differential equations proposed in this study were successfully used.
\end{abstract} optimization.

Keywords: CSTR reactor modeling, chemical reaction, numerical methods, sizing,

\section{INTRODUCTION}

CSTR (continuous stirred tank reactor) reactors are used in chemical processes for mixing, reactions e crystallizations, has as main characteristic the continuous flow of reactants and products [1].

The Fig. 1 [3], represents a CSTR reactor, along with a cooling jacket. 


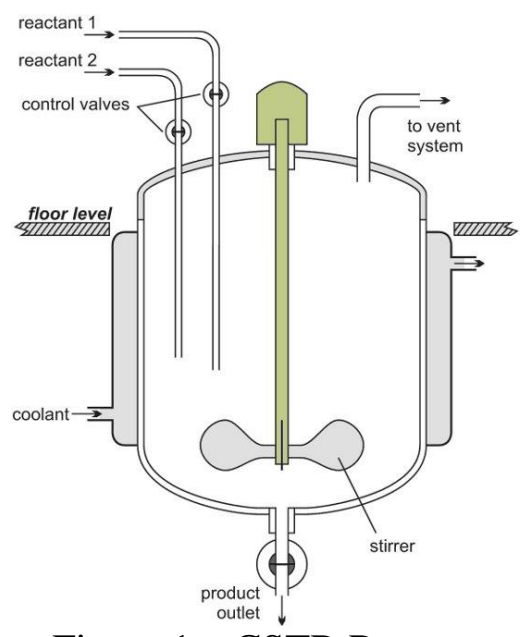

Figure 1 - CSTR Reactor

The CSTR can be considered a basic chemical reactor. Its size can vary from a few liters to thousands of liters. They are used for various reactions involving the three states of matter: liquid, gas, or solid, when it uses catalysts [2].

The design of CSTR reactors is of extreme importance for the industry, since several types of reactions pass through it and, having ideal parameters that express a better efficiency, means less energy expenditure and greater production.

For this work numerical methods such as Euler and Runge-Kutta were used to solve differential equations. These equations relate parameters that take place on a chemical reaction, such as enthalpy, temperature, concentration and reaction rate. The use of numerical methods was needed because of the number of unknown variables. Transient state was considered for the mentioned methods.

In the Euler Method, which was introduced in a three-volume work, a sequence of approximations $\mathrm{y}_{1}, \mathrm{y}_{2}, \mathrm{y}_{3} \ldots$ to the solution of a differential equation at $\mathrm{x}_{1}, \mathrm{x}_{2}, \mathrm{x}_{3} \ldots$ is intended to eventually lead to the approximate and correct value [4].

Runge-Kutta is also an approximation but, being established way later, at the beginning of the $20^{\text {th }}$ century, it results in much more accurate results [4].

The design of a CSTR reactor implies the evaluation of conditions that can be controlled and improved. When studying this type of subject, the engineer can avoid unnecessary losses and promote the maximum use of the raw material being used. The study of the mathematical equations that define certain behaviors within the CSTR reinforce the need to understand parameters such as temperature, pressure and reaction rate.

\section{Experimental}

Using as a starting point, a chemical reaction where $\mathrm{A}$ becomes $\mathrm{B}$, and considering volume as a constant inside the reactor, the mass balance was made in Eqs. 1 and 2, to obtain the parameters of concentration inside the reactor with time. The energy balance was made, and it's represented in Eq. 3, where the parameter of temperature with time is the one that should and will be considered for the numerical methods.

$$
\begin{array}{r}
\frac{V d C a}{d t}=q . C a e-q \cdot C a-\text { K.Ca.V } \\
\frac{V d C b}{d t}=-q \cdot C b+\text { K.Ca.V }
\end{array}
$$


$\rho \cdot V \cdot C p \cdot \frac{d T}{d t}=q \cdot \rho \cdot C p \cdot(T e-T)+U \cdot A \cdot(T c-T)+\dot{\mathrm{W}}+\dot{\mathrm{R}} \mathrm{t}+\mathrm{V}$

For these three, Board 1 was made to determine each parameter in the equations.

Board 1 - Constant Description

\begin{tabular}{|c|c|c|c|}
\hline $\mathbf{V}$ & Volume & $\mathbf{T}$ & Temperature at any time inside the reactor \\
\hline $\mathbf{K}$ & Reaction constant & $\mathbf{T e}$ & Starting Temperature \\
\hline $\mathbf{C a}$ & Concentration of component A & $\mathbf{P}$ & Specific mass \\
\hline $\mathbf{C b}$ & Concentration of component A & $\mathbf{U}$ & Coeficient of heat transfer \\
\hline $\mathbf{A}$ & Area of Reactor & $\mathbf{D t}$ & Time variation \\
\hline $\mathbf{C p}$ & Specific Heat & $\mathbf{T c}$ & Temperature inside the cooling jacket \\
\hline $\mathbf{R t}$ & Rate of heat exchange & $\mathbf{Q}$ & Volumetric flow \\
\hline
\end{tabular}

Source: Author, 2017.

Due to the quatity of parameters Pinto (2001), proposed a series of adimensionalizations for the equations. Eqs. 4 through 11, represent that.

$$
\begin{aligned}
& \mathrm{Xa}=\frac{\mathrm{Ca}}{\mathrm{Cae}} \\
& \mathrm{Xb}=\frac{\mathrm{Cb}}{\mathrm{Cae}} \\
& \theta=\frac{\mathrm{V}}{\mathrm{q}} \\
& \theta \mathrm{r}=\mathrm{Ko.} \theta \\
& \Delta \mathrm{Er}=\frac{\Delta \mathrm{E}}{\mathrm{R} \cdot \mathrm{T}} \\
& \beta=\mathrm{U} \cdot \frac{\mathrm{A}}{\mathrm{q} \cdot \mathrm{C. \textrm {Cp }}} \\
& -\Delta \mathrm{hr}=\frac{\mathrm{Cae} \cdot-\Delta \mathrm{Hr}}{\rho . \mathrm{Cp} \cdot \mathrm{Te}} \\
& \gamma=\frac{\mathrm{T}}{\mathrm{Te}}
\end{aligned}
$$

For these equations, it was possible to obtain three more, with the differential terms isolated for further application of the numerical methods. Eqs 12, 13 and 14 represent the differential terms $\mathrm{Xa}, \mathrm{Xb}$ and $\gamma$ respectively. 


$$
\begin{gathered}
\frac{\mathrm{dXa}}{\mathrm{dt}}=1-\mathrm{Xa}-\theta \mathrm{r} * \mathrm{Xa} * \exp \left(-\frac{\Delta \mathrm{Er}}{\gamma}\right) \\
\frac{\mathrm{dXb}}{\mathrm{dt}}=-\mathrm{Xb}+\theta \mathrm{r} * \exp \left(-\frac{\Delta \mathrm{Er}}{\gamma}\right) \\
\frac{\mathrm{d} \gamma}{\mathrm{d} \tau}=(1-\gamma)+\text { U. } \beta \cdot(\gamma \mathrm{c}-\gamma)+\theta \text { r. } \Delta \text { hr. Xa. } \exp \left(-\frac{\Delta \mathrm{Er}}{\gamma}\right)
\end{gathered}
$$

To start the experiment, equation 14 had its differential term considered zero, so the reaction was stationary. After that, the bisection method was used to solve it and by having the value for gamma, the numerical values for $\mathrm{Xa}$ and $\mathrm{Xb}$ were obtained using the analytical solution with simple equations (no differential terms).

After that, Euler and Runge-Kutta were applied, and the values obtained were compared with the analytical solution to validate the use of Eqs. 12, 13 and 14. To demonstrate the results, tables and slopes were elaborated for this work, using Excel as main tool.

\section{RESULTS AND DISCUSSION}

As said previously, with Eq.14 having its differential terms equal to zero, bisection was used to solve it. Table 1, represents the data used for the terms ins the equation.

Table 1 - Values for Eq.14

\begin{tabular}{ccccc}
\hline Beta & $\Delta \mathrm{Er}$ & $\Delta \mathrm{Hr}$ & $\Theta \mathrm{r}$ & $\gamma \mathrm{c}$ \\
\hline 1 & 10 & 10 & 50 & 1 \\
\hline
\end{tabular}

Table 2 represents the bisection method, after inserting the numbers above in equation 14.

Table 2 - Bisection method to find $\gamma$

\begin{tabular}{cccccccc}
\hline $\mathbf{A}$ & $\mathbf{B}$ & $\mathbf{P}$ & $\mathbf{f}(\mathbf{a})$ & $\mathbf{f}(\mathbf{b})$ & $\mathbf{f}(\mathbf{p})$ & $\mathbf{f ( a ) . f ( p )}$ & erro \\
\hline 5,0000 & 10,0000 & 7.5000 & 0,7125 & $-8,5156$ & $-3,7052$ & $-2,6398$ & \\
5,0000 & 7,5000 & 6.2500 & 0,7125 & $-3,7052$ & $-1,4013$ & $-0,9984$ & 2,5000 \\
5,0000 & 6,2500 & 5.6250 & 0,7125 & $-1,4013$ & $-0,3081$ & $-0,2195$ & 1,2500 \\
5,0000 & 5,6250 & 5.3125 & 0,7125 & $-0,3081$ & 0,2138 & 0,1523 & 0,6250 \\
5,3125 & 5,6250 & 5.4688 & 0,2138 & $-0,3081$ & $-0,0447$ & $-0,0095$ & 0,3125 \\
5,3125 & 5,4688 & 5.3906 & 0,2138 & $-0,0447$ & 0,0852 & 0,0182 & 0,1563 \\
5,3906 & 5,4688 & 5.4297 & 0,0852 & $-0,0447$ & 0,0204 & 0,0017 & 0,0781 \\
5,4297 & 5,4688 & 5.4492 & 0,0204 & $-0,0447$ & $-0,0121$ & $-0,0002$ & 0,0391 \\
5,4297 & 5,4492 & 5.4395 & 0,0204 & $-0,0121$ & 0,0042 & 0,0001 & 0,0195 \\
5,4395 & 5,4492 & 5.4443 & 0,0042 & $-0,0121$ & $-0,0039$ & 0,0000 & 0,0098 \\
5,4443 & 5,4492 & 5.4468 & $-0,0039$ & $-0,0121$ & $-0,0080$ & 0,0000 & 0,0049 \\
\hline \multicolumn{2}{l}{ Source: Author, 2017. } & & & & & &
\end{tabular}

So with a value for gamma, the analytical equations were utilized for $\mathrm{Xa}$ and $\mathrm{Xb}$. 


$$
\begin{aligned}
& \mathrm{Xa}=\frac{1}{1+\theta \mathrm{r} * \exp \left(-\frac{\Delta \mathrm{Er}}{\gamma}\right)} \\
& \mathrm{Xb}=\frac{\theta \mathrm{r} * \exp \left(-\frac{\Delta \mathrm{Er}}{\gamma}\right)}{1+\theta \mathrm{r} * \exp \left(-\frac{\Delta \mathrm{Er}}{\gamma}\right)}
\end{aligned}
$$

With $\mathrm{Xa}=0.111$ and $\mathrm{Xb}=0.888$.

Then, differential equations were used, to check if they were valid or not and how sensitive each parameter was. At first the values from table 1 were applied in Eqs. 12, 13 and 14 , but didn't result on anything close to the analytical solution neither did it make sense mathematically. So, some subtle changes were made in those values, to check how it would respond. So, for $\Delta \mathrm{Er}=8.499$ instead of 10 , and $\theta \mathrm{r}=52.909$ instead of 50, the equation was valid and Table 3 represents the results.

Table 3 - Values for the Numerical Methods

\begin{tabular}{cccccc}
\hline \multicolumn{3}{c}{ For Euler } & \multicolumn{3}{c}{ For Runge Kutta } \\
$\mathbf{X a}$ & $\mathbf{X b}$ & $\boldsymbol{\Gamma}$ & $\mathbf{X a}$ & $\mathbf{X b}$ & $\boldsymbol{V}$ \\
\hline 0.07914 & 0.92086 & 5.61019 & 0.07908 & 0.93958 & 5.61152 \\
\hline Source: Author, 2017.
\end{tabular}

A step of 0,05 was used for the methods and 251 iterations were necessary for the result with error less than 0.001. Graphic 1 shows the slopes for Euler and Runge-Kutta using the information from Table 3.

Graphic 1 - Slopes for Numerical Methods

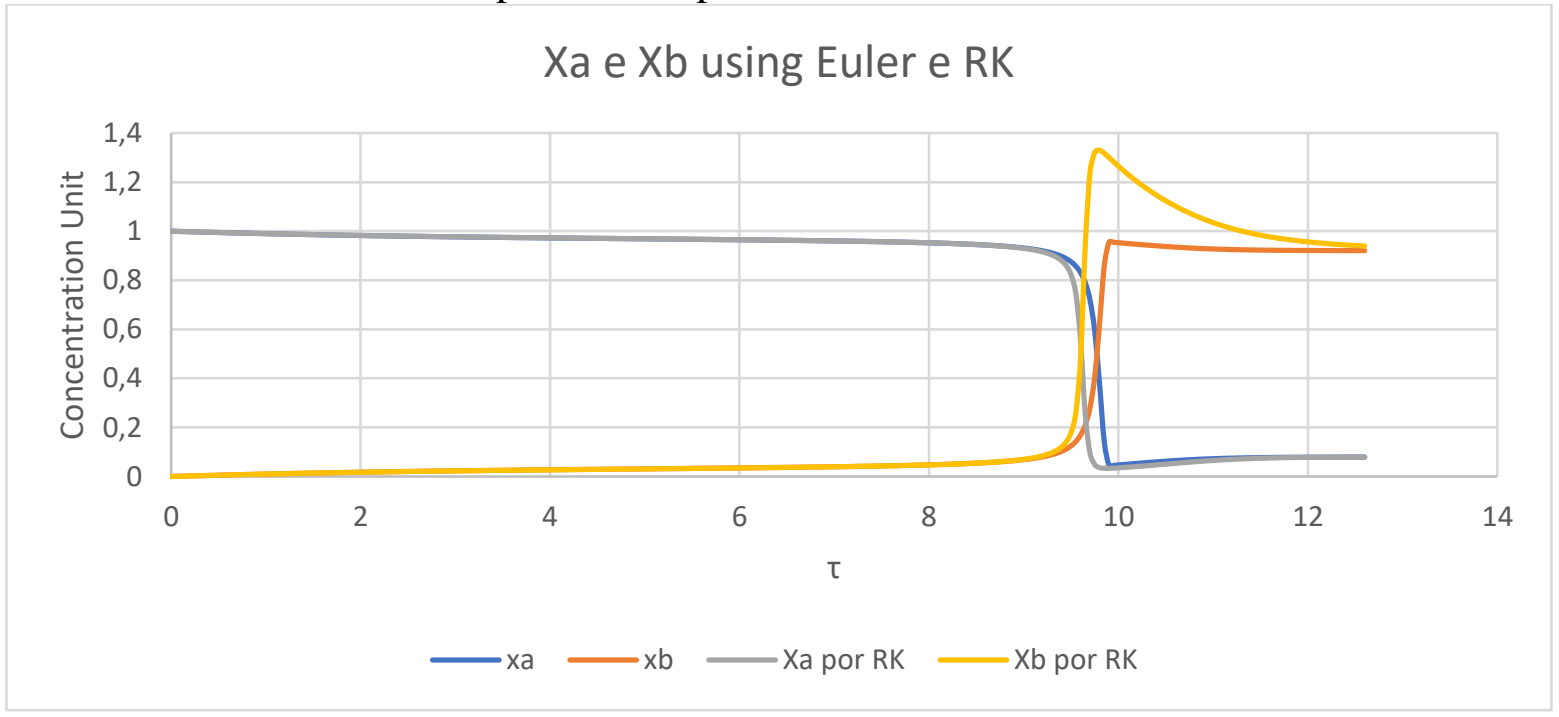

Source: Author, 2017.

Graphic 2 represents the slopes of gamma, which shows the variation of temperature inside the reactor at any given time. 
Graphic 2 - Slopes for gamma using numerical methods

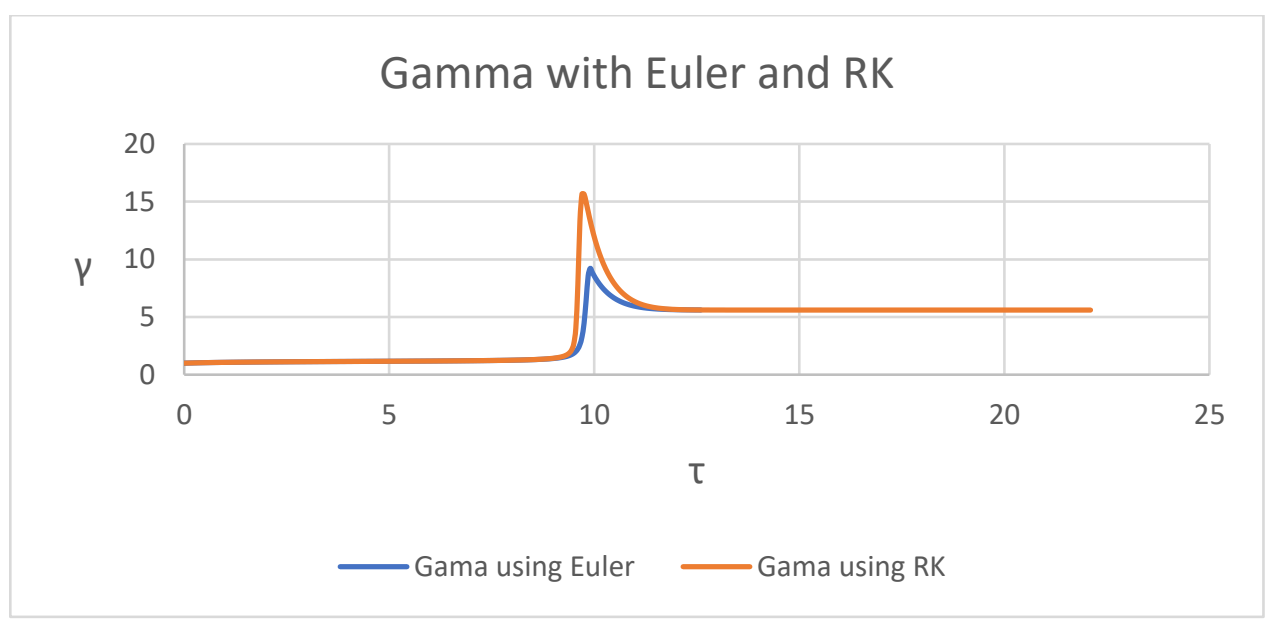

Source: Author, 2017.

The variation between methods, can be explained due to the sensibility of RK, being much bigger than Euler, and the curve for gamma goes much higher than the simpler method.

The previous data is solved based on values coming straight from Pinto's book, so to ensure the validity of the equations, the reaction of cyclopropane $\rightarrow$ propene, was also studied. This reaction also has its volume as a constant, so the equations mentioned before can be used as well. Graphic 3 represents $\mathrm{Xa}, \mathrm{Xb}$ and $\gamma$.

Graphic 3 - Slopes of parameters for cyclopropane $\rightarrow$ propene

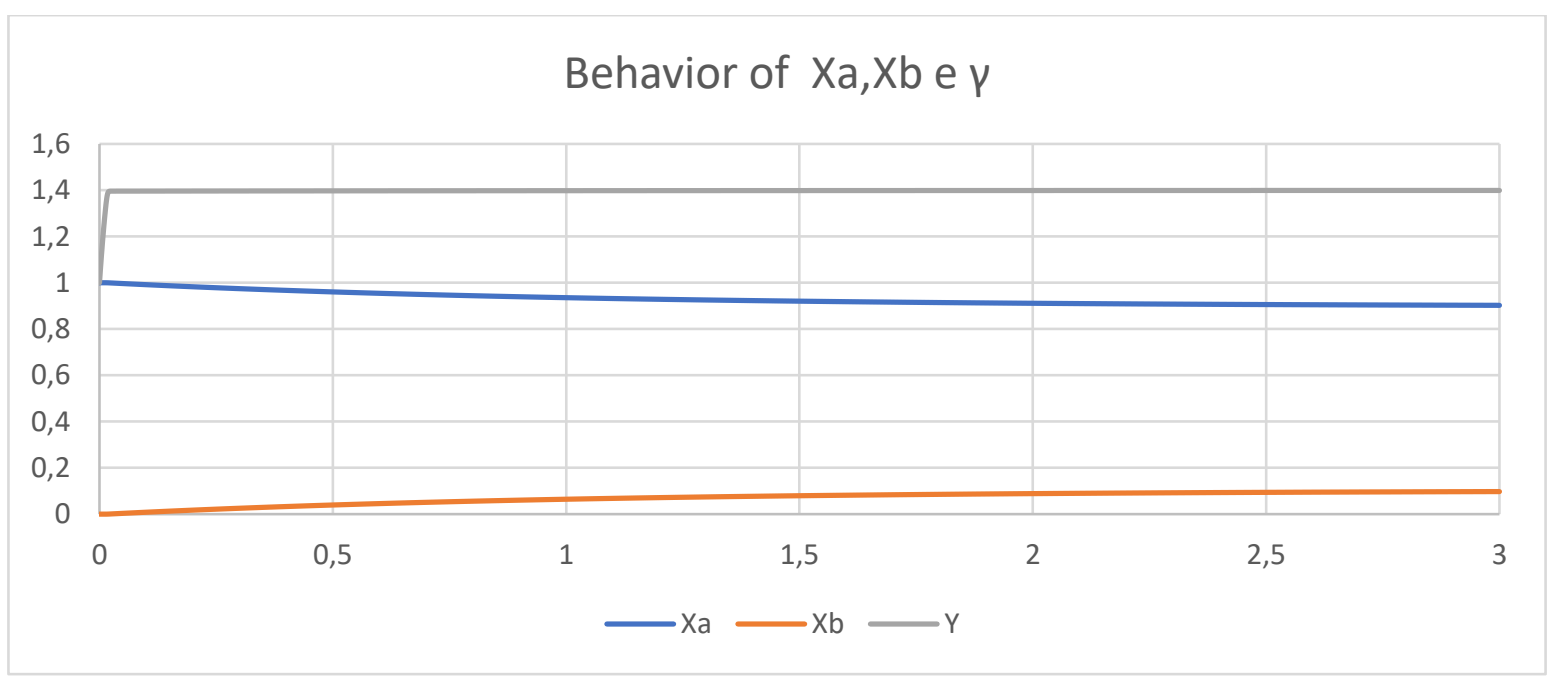

Source: Author, 2017.

Even though the slopes do not represent a big production of propene, they confirm that that differential equations used are valid and can be used for further works, taking into accounting their sensibility in changing of values for each parameter.To show that Graphic 4 represents what kind of changes can happen if we change (in this case increase), the parameter values for thes equations. For a $10 \%$ increase, was evaluated how much gamma would vary from its equilibrium condition. 
Graphic 4 - Parameter Evaluation

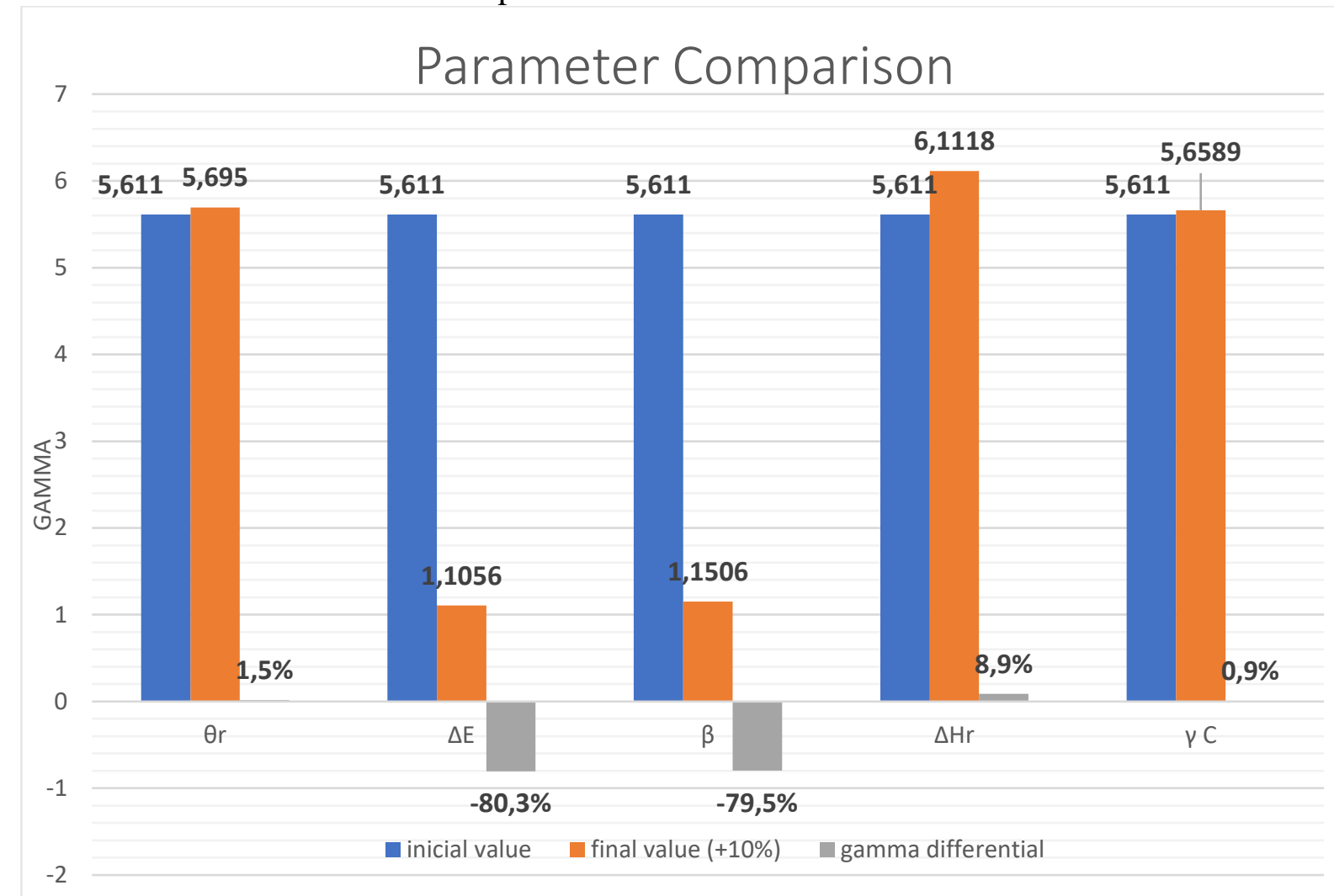

Source: Author, 2018.

With that we can conclude that $\Delta \mathrm{E}$ and $\beta$ are more sensitive to changes and influence temperature differential inside the reactor more than the others.

A little observation to be made, is that the excel tool writes the numbers with a comma, because it's a Brazilian version, but those should be considered dots, for the International standards.

\section{CONCLUSION}

For the example using data from Pinto (2001), the differential equations showed to be valid, and for small changes made on the values of $\beta$, and $-\Delta \mathrm{E}$, represented a big difference in the parameters $\mathrm{Xa}, \mathrm{Xb}$ and $\gamma$.

The same was seen in the reaction of obtention of propene. For this one, it was also concluded that gas reactions that have same stoichiometric number (for reactants and products) are also valid for the equations used in this work, since volume is also constant.

Runge-Kutta in comparison to Euler had a satisfactory behavior and it made possible to see the big jump in temperature inside the reactor, something that Euler didn't show as much for the same data. 


\section{ACKNOWLEDGEMENTS}

To professor Emerson Martim, to give me the opportunity to work with him in the PIBIC project and for having pushed me to do better and expect better results of myself.

To UFPR, for the invitation, and to recognize my work and its quality.

To my parents and friends, for being so kind and always support my choices.

\section{REFERENCES}

1. BUTCHER, J C. Numerical Methods for Ordinary Differential Equations. 2. ed. new zeland: John Wiley and Sons ltd, v. 1, 2008. Disponível em: $<$ file:///C:/Users/Matheus/Downloads/Numerical-methods-for-ordinary-differentialequations.pdf>. Acess in: 19 fev. 2018.

2. Essential Chemical Industry.Chemical Reactors. Disponível em:< http://www.essentialchemicalindustry.org/processes/chemical-reactors.html >. Acess in: Feb, 2018.

3. Igbokwe, Philomena K.; Nwabanne, Joseph T.; Gadzama, Samuel Wadzani. Characterization of a 5 Litre Continuous Stirred Tank Reactor. Enugu,Nigeria: Departmento de Engenharia Química, Universidade de Nnamdi Azikiwe,v. 3,, p. 25-40, abril. 2015.

4. NANDA, S. Reatores e Fundamentos de Design de Reatores para Reação Química. Departamento de Ciencias Farmaceuticas, Rohtak, p. 8, 2008. Disponível: em< http://www.eng.unideb.hu/userdir/deak.krisztian/REACTORS+AND+FUNDAMENTALS+O F\%20highlighted.pdf $>$. Acess in : 06 dez. 2016.

5. PINTO, José Carlos; Lage, Paulo Laranjeira da Cunha; Métodos Numéricos em problemas da Engenharia Química. ${ }^{a}{ }^{a}$ Edição. Rio de Janeiro: Rio Janeiro,2001 